\title{
MEASUREMENTS OF NITRIC OXIDE DURING A STRATOSPHERIC WARMING
}

\author{
W. Knight, D.R. Hastie and B.A. Ridley
}

Department of Chemistry, York University, Downsview, Ontario, Canada, M3J IP3

Abstract. The altitude distribution of NO was measured between 12 and $33 \mathrm{~km}$ near $54^{\circ} \mathrm{N}$ during the stratospheric warming of February, 1979. The NO mixing ratios were considerably smaller compared to summer conditions, especially below 23 $\mathrm{km}$. The measurements are used to estimate the distribution of $\mathrm{NO}_{2}$ for comparison with groundbased column measurements and to show that during the warming $\mathrm{NO}_{x}$ is at least a factor of two lower than is observed in summer at this latitude. This reduction in $\mathrm{NO}_{\mathbf{x}}$ is shown to be consistent with a larger fraction of odd-nitrogen existing as $\mathrm{N}_{2} \mathrm{O}_{5}$.

\section{Introduction}

The stratospheric warming of January and February 1979 has been the subject of several recent studies. Quiroz (1979) has analyzed the physical properties of the warming. Hilsenrath (1980) has reported several rocket ozone-sonde profiles. Noxon et al. $(1979,1980)$ have reported ground-based measurements of stratospheric $\mathrm{NO}_{2}$ in a portion of the normally zonal polar vortex flow that was displaced well south of its usual location over the pole. Here a measurement of the altitude distribution of No obtained during the warming is reported. This occurred fortuitously as part of a three year program (1977-1979) to investigate seasonal changes in odd-nitrogen species at northern latitudes. The York University balloon payload was 1aunched from Canadian Forces Base, Cold Lake, Alberta $\left(110^{\circ} \mathrm{W}, 54.4^{\circ} \mathrm{N}\right)$ on Feb. $11 / 79$ at 1306 LT $(2006 \mathrm{Z})$. Measurements of No were obtained with a chemiluminescence instrument that has been described elsewhere (Ridley and Schiff, 1981).

A scanning radiometer for measurements of $\mathrm{HNO}_{3}$, operated by the Atmospheric Environment Service (AES), was included in the payload. Results from that instrument and ground-based measurements of $\mathrm{NO}_{2}$ are reported by Evans et al. (1982).

\section{Observations}

The No mixing ratios measured on ascent and during the float period are shown in Figs. 1 and 2. Included in Fig. 1, for comparison, is an average of several summer profiles measured near this latitude (Ridley and Hastie, 1981). The winter mixing ratios are smaller at a11 altitudes but particularly in the low to mid-stratosphere where from 12 to $18 \mathrm{~km}$, at $20 \mathrm{~km}$ and at $23 \mathrm{~km}$ they are 2-3, 4 and 6 times lower than in summer, respectively. This difference would be amplified if the data were plotted relative to the respec-

Copyright 1982 by the American Geophysical Union.

Paper number 2L0347.

$0094-8276 / 82 / 002 \mathrm{~L}-0347 \$ 3.00$ tive tropopause altitudes. Although the present measurements were made during a warming, the winter profile bears a qualitative resemblance to those obtained from the same location in February 1977 and 1978. A comparison of the three winter profiles will be presented elsewhere, but common features show low No compared to summer below 23-26 km accompanied by a rapid increase to values comparable to those of summer in the 29-33 km region. However, the onset of this rapid increase varied from year to year and in 1977 there was a peak near $14 \mathrm{~km}$.

Figs. 3 and 4 present a temperature profile and $\mathrm{O}_{3}$ mixing ratios measured by the AES. The extent of the warming is illustrated by a comparison of the 1979 temperature profile with one from the 1978 campaign, a normal winter profile, and with one from summer at $51^{\circ} \mathrm{N}$ (Ridley and Hastie, 1981). In contrast, the winter mixing ratios of $0_{3}$ are similar except for structure near $14 \mathrm{~km}$ and lower mixing ratios above $29 \mathrm{~km}$ in 1979 . As expected, both winter profiles exhibit much larger mixing ratios in the lower stratosphere compared to summer conditions.

\section{Discussion}

The time constant for daytime partitioning of $\mathrm{NO}_{\mathrm{x}}\left(\mathrm{NO}+\mathrm{NO}_{2}\right)$ is only a few minutes so that trans-

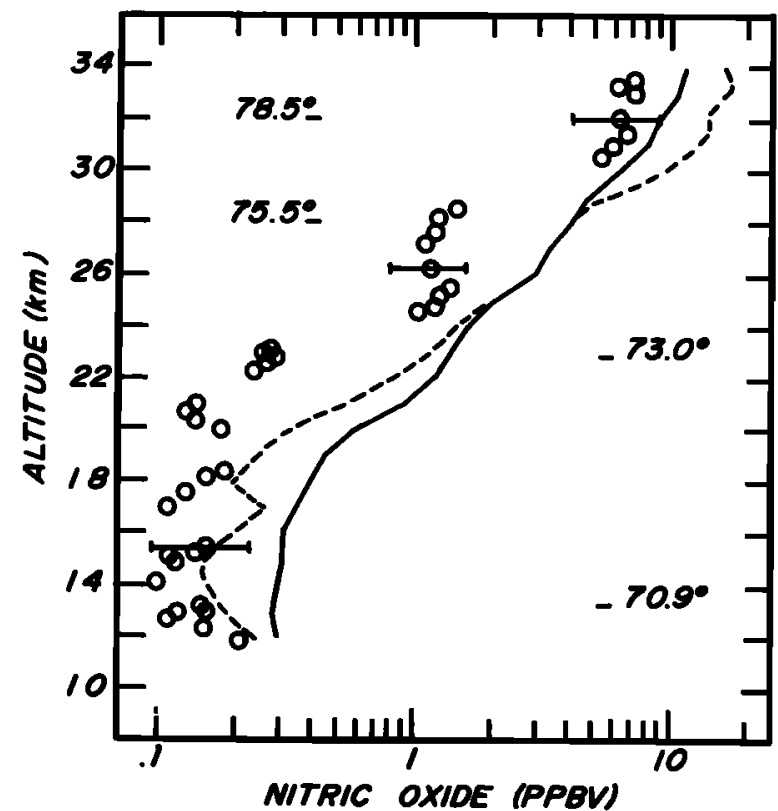

FIg. 1. The mixing ratio of nitric oxide measured on ascent (open circles). The solar zenith angle $(x)$ is indicated to the right and left of the data. The solid line is the average NO from several summer flights near this latitude. The dashed curve is described in the text. 


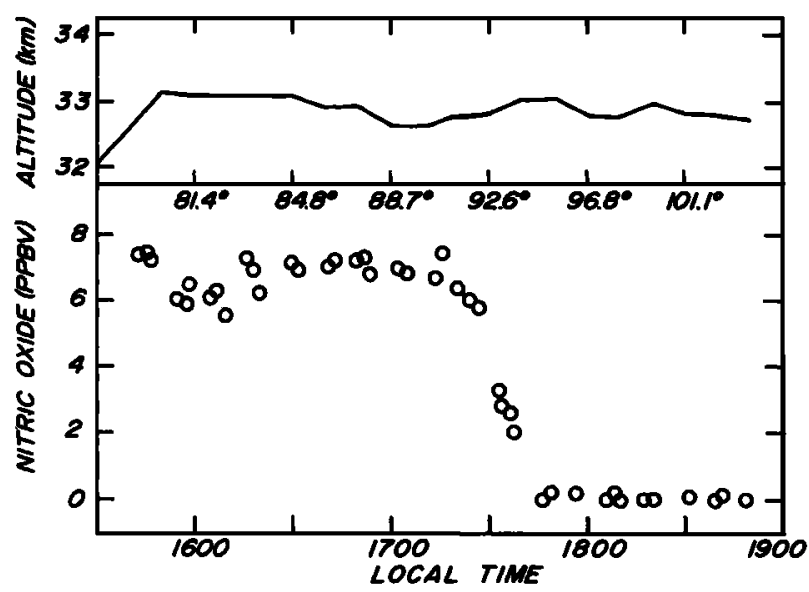

Fig. 2. The decay of No during sunset. The solar zenith angle was calculated for the balloon position.

port processes may be ignored. Changes in the partitioning between summer and winter warming conditions can then be examined on the basis of differences in insolation, temperature, and the abundance of $\mathrm{O}_{3}$. In winter, decreased insolation and increased $\mathrm{O}_{3}$ densities below about $23 \mathrm{~km}$ favour larger amounts of $\mathrm{NO}_{2}$. The higher temperatures at lower altitudes during the warming amplify this tendency to $\mathrm{NO}_{2}$.

These effects can be examined quantitatively if it is assumed that $\mathrm{NO}_{\mathbf{X}}$ is conserved between the sumer season and the winter warming period. The average summer NO profile of Fig. 1 was used to compute $\mathrm{NO}_{\mathbf{X}}$ for the summer conditions of temperature and $\mathrm{O}_{3}$ assuming the usual photochemical steadystate relation for the $\mathrm{NO}_{2} / \mathrm{NO}$ ratio (cf. Ridley and Hastie, 1981). The photodissociation coefficient of $\mathrm{NO}_{2}$ was calculated using a multiple scattering routine and a $25 \%$ surface albedo (Madronich et a1., 1982). This calculated summer $\mathrm{NO}_{x}$ was then subjected to the winter warming insolation, temperature and $0_{3}$ conditions of $\mathrm{Feb} .11 / 79$. The calculated winter NO, shown as the dashed curve of Fig. 1, approaches that measured at the lowest altitudes mainly due to increased $0_{3}$ oxidation in winter but is still significantly largex than was observed at higher altitudes. Furthermore, the calculated winter $\mathrm{NO}_{2}$, corresponding in time to the dashed curve of Fig. 1, yields a column amount of $5.5 \times 10^{15} \mathrm{~cm}^{-2}$. This daytime $\mathrm{NO}_{2}$ column is about twice that measured by the AES at evening twilight at the launch site (Evans et al., 1982) and also about twice as large as would be interpolated from evening measurements of $4 \times 10^{15} \mathrm{~cm}^{-2}$ at $50^{\circ} \mathrm{N}$ and $2 \times 10^{15} \mathrm{~cm}^{-2}$ at $65^{\circ} \mathrm{N}$ reported by Noxon $(1979,1980)$ for a warming event in Jan. 1978 when the stratospheric flow pattern was simflar to that prior to the present balloon flight. Thus the winter warming NO profile is not solely a reflection of differences in $\mathrm{NO}_{\mathrm{x}}$ partitioning but indicates a substantial reduction in $\mathrm{NO}_{\mathbf{x}}$ from summer to winter warming conditions.

The magnitude of the winter warming reduction in $\mathrm{NO}_{\mathrm{x}}$ can be examined in more detail if the measured No profile is used to estimate the abundance of $\mathrm{NO}_{2}$ during the warming. This also allows a comparison to be made between ground- based measurements of the column abundance of $\mathrm{NO}_{2}$ and that inferred from the observed No profile.

Fig. 5 presents the $\mathrm{NO}_{2}$ profile, corresponding in time to the measured No, calculated as described above from the steady-state $\mathrm{NO}_{2}$ /NO ratio using the measured $\mathrm{O}_{3}$ and temperature distributions of the warming. A comparison with ground-based measurements requires the conversion of this mid afternoon profile to that for twilight conditions. Evening $\mathrm{NO}_{2}$ was estimated by summing daytime measured $\mathrm{NO}$ and calculated $\mathrm{NO}_{2}$ and partitioning this according to the photodissociation coefficient at $x=90^{\circ}$. As the photodissociation of ambient $\mathrm{N}_{2} \mathrm{O}_{5}$ is very slow, the small release of $\mathrm{NO}_{x}$ from $\mathrm{N}_{2} \mathrm{O}_{5}$ during the late afternoon was neglected. Morning twilight $\mathrm{NO}_{2}$ was estimated by incorporating the expected formation of $\mathrm{N}_{2} \mathrm{O}_{5}$ during the long night and partitioning the remaining $\mathrm{NO}_{x}$ for $\mathrm{X}=90^{\circ}$ in the morning. The estimated colum densities of $\mathrm{NO}_{2}$ for morning twilight, mid afternoon and evening twilight are in units of $10^{15} \mathrm{~cm}^{-2}, 1.2,2.7$ and 3.0 , respectively. The twilight estimates are in good agreement with those reported for the balloon campaign by Evans et al. (1982), those of Syed and Harrison (1981) for Calgary, some $450 \mathrm{~km}$ south west of Cold Lake and those of Noxon (1979, 1980) for the 1978 warming referred to earlier. The daytime winter warming $\mathrm{NO}_{x}$ column abundance is then $\sim^{5} \times 10^{15} \mathrm{~cm}^{-2}$ (NO: $2 \times 10^{15} \mathrm{~cm}^{-2} ; \mathrm{NO}_{2}$ : $2.7 \times 10^{15} \mathrm{~cm}^{-2}$ ). In summer at these latitudes a typical value is $\approx 11 \times 10^{15} \mathrm{~cm}^{-2}$ (NO: $4.5 \times 10^{15}$ $\mathrm{cm}^{-2}$, Ridley and Hastie, $1981 ; \mathrm{NO}_{2}: 6 \times 10^{15} \mathrm{~cm}^{-2}$, Evans et al., 1982). Thus $\mathrm{NO}_{x}$ during the warming remained at least a factor of two below that observed in summer.

The seasonal difference in the abundance of

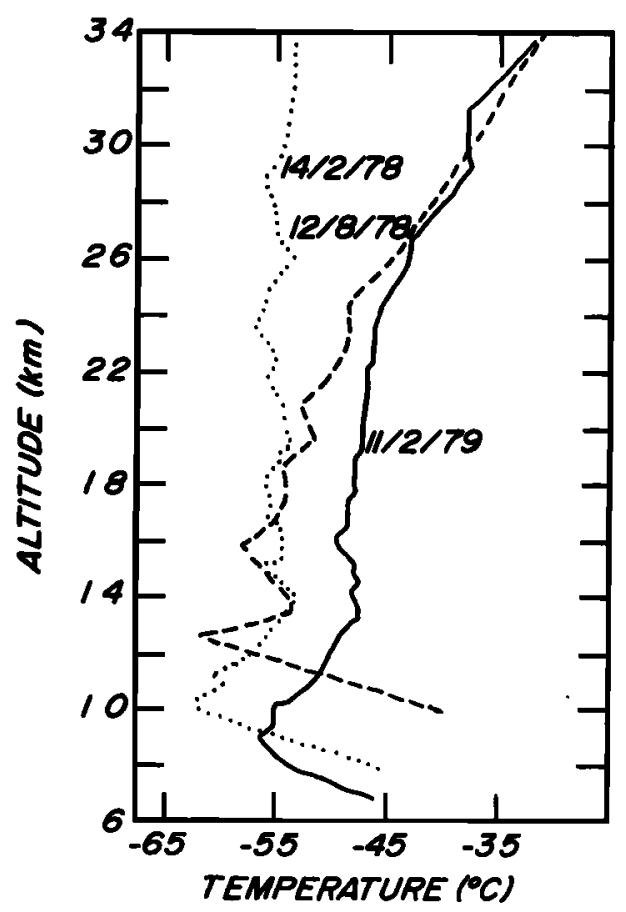

Fig. 3. A comparison of the atmospheric temperature profile for the present flight with one for summer near this latitude and with one obtained during a balloon flight on Feb. $14 / 78$ when no warming was present. 
NO $O_{x}$ at northern latitudes may result from a combination of transport and conversion to a winter storage reservoir. Current chemistry suggests that $\mathrm{HNO}_{3}, \mathrm{HNO}_{4}$ and $\mathrm{N}_{2} \mathrm{O}_{5}$ are possible reservoirs and Evans et al. (1982) use their measurements of $\mathrm{HNO}_{3}$ to examine the suggestion by Noxon et al. (1979) that $\mathrm{HNO}_{3}$ is the principal reservoir. On the other hand, $\mathrm{N}_{2} \mathrm{O}_{5}$ chemistry alone can account for both the diurnal change in $\mathrm{NO}_{2}$ and the reduction in $\mathrm{NO}_{\mathrm{x}}$ during a warming. At $54^{\circ} \mathrm{N}$ in winter, the diurnally averaged photodissociation lifetime of $\mathrm{N}_{2} \mathrm{O}_{5}$ is about 3 days. Thus the long winter nights, the high $0_{3}$ densities in the lower stratosphere and the higher temperatures should combine to increase the fraction of odd-nitrogen that is present as $\mathrm{N}_{2} \mathrm{O}_{5}$ compared to summer conditions if an air mass spends only a few days near or north of the latitude of Cold Lake. This would be anticipated even if the air mass originated from latitudes south of Cold Lake.

The stratospheric circulation during the warming was unstable and so it is difficult to accurately determine the time the air mass sampled during the balloon flight resided near or north of Cold Lake. Upper air charts indicated that Cold Lake was near the edge of the flow about the polar low pressure region below about $22 \mathrm{~km}$ for several days prior to the flight. At higher altitudes and for several days prior to the flight the polar low was distorted by a high pressure region over Alaska and $1 t$ is possible that the sampled air originated in part from latitudes south of $50^{\circ} \mathrm{N}$ and west of the high pressure region.

However, the clockwise flow west of the high towards the pole was quite weak. Eastward of the high, the flow southwards towards Cold Lake was weaker still. Consequently, the transit time for flow from $50^{\circ} \mathrm{N}$ poleward about the high to $65-70^{\circ} \mathrm{N}$ and southward to Cold Lake was estimated at just over 4 days. Thus, even if the air mass followed

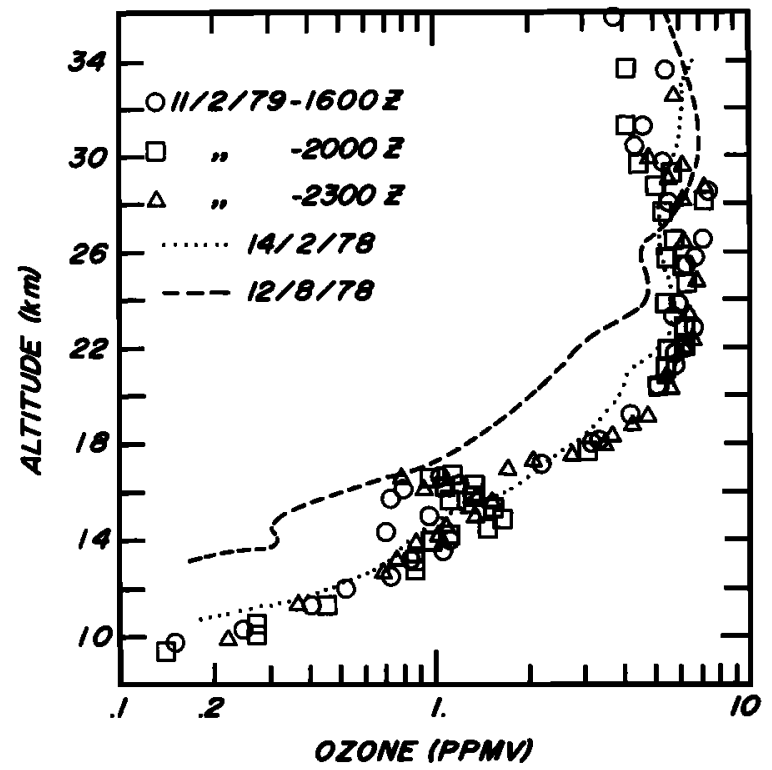

Fig. 4. A comparison of the ozone mixing ratio from three sondes launched by the AES on the day of the balloon flight with that obtained on previous flights as described in Fig. 3 .

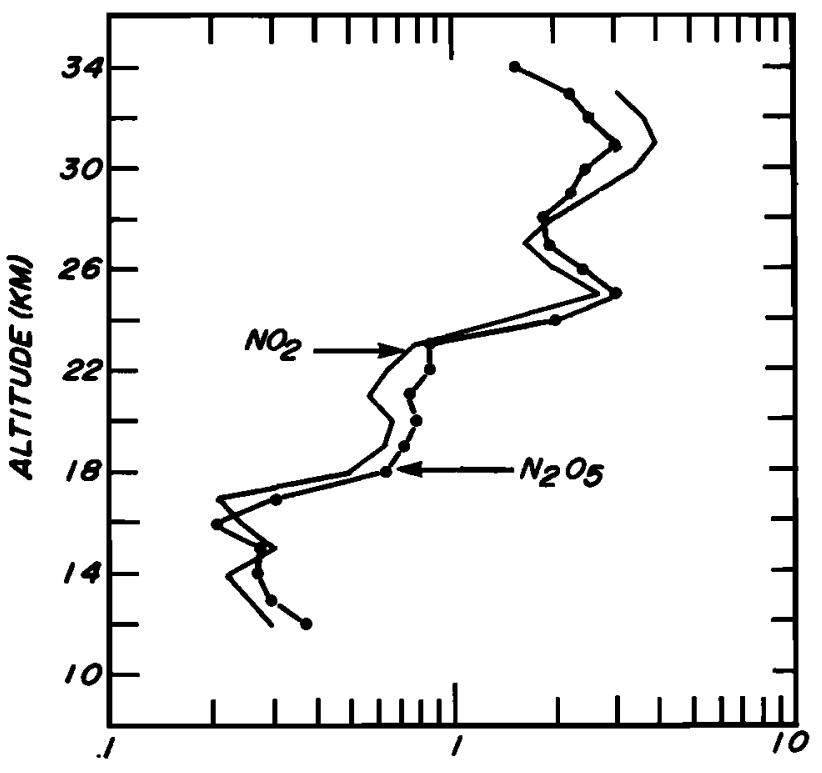

CALCULATED MIXING RATIO (PPBV)

Fig. 5. Estimated steady -6 tate mixing ratios of $\mathrm{NO}_{2}$ and $\mathrm{N}_{2} \mathrm{O}_{5}$ derived from the winter No profile.

this route alone, a large conversion of $\mathrm{NO}_{\mathrm{x}}$ to $\mathrm{N}_{2} \mathrm{O}_{5}$ would be anticipated.

The expected steady-state abundance of $\mathrm{N}_{2} \mathrm{O}_{5}$ is given in Fig. 5. This was estimated by determining the $\mathrm{N}_{2} \mathrm{O}_{5}$ /NO ratio from a one-dimensional diurnal model (J.C. McConnell, private communication) run for the flight conditions of $O_{3}$ temperature and the time of the measured NO. The $\mathrm{N}_{2} \mathrm{O}_{5}$ distribution of Fig. 5 yields a column abundance for the afternoon of $2.9 \times 10^{15} \mathrm{~cm}^{-2}$, comparable to that of evening $\mathrm{NO}_{2}$. Combining this with measured column NO and calculated afternoon column $\mathrm{NO}_{2}$ yields an $\mathrm{NO}_{\mathrm{x}}+2 \mathrm{~N}_{2} \mathrm{O}_{5}$ daytime abundance of $\sim 11 \times 10^{15} \mathrm{~cm}^{-2}$. A typical value for summer conditions near this latitude is $13 \times 10^{15}$ $\mathrm{cm}^{-2}$ derived using the previous estimate of summer $\mathrm{NO}_{\mathrm{x}}$ and taking $\mathrm{N}_{2} \mathrm{O}_{5}$ as $1.2 \times 10^{15} \mathrm{~cm}^{-2}$ from similar model calculations. Within these estimates it would appear that current model chemistry can account for the seasonal change in $\mathrm{NO}_{\mathrm{x}}$ and the observed diurnal change in $\mathrm{NO}_{2}$. This, of course, does not rule out the possibility of slow conversion of $\mathrm{NO}_{x}$ to $\mathrm{HNO}_{3}$ during long term and stable polar circulation conditions.

An $\mathrm{N}_{2} \mathrm{O}_{5}$ reservoir is also consistent with Noxon's constraint (1979) that the winter reservoir must release $\mathrm{NO}_{x}$ photolytically upon transport to lower latitudes. An upper limit for the colum abundance of $\mathrm{N}_{2} \mathrm{O}_{5}$ above $18 \mathrm{~km}$ of $2 \times 10^{14}$ $\mathrm{cm}^{-2}$ has been reported by Murcray et al. (1978) for $57^{\circ} \mathrm{N}$ in February 1978. This limit is more than a factor of 10 below our estimate and if it should survive measurements designed specifically to measure $\mathrm{N}_{2} \mathrm{O}_{5}$ then the storage reservoir(s) remains to be identified. $\mathrm{HNO}_{3}$ cannot explain the observed diurnal variation in $\mathrm{NO}_{2}$ column abundance and so cannot be the only reservolx species. HNO 4 has a photolysis time constant similar to that for $\mathrm{N}_{2} \mathrm{O}_{5}$ but current models estimate too small an abundance to account for the magnitude of the diurnal change. 
Acknowledgments. We thank the personnel at the Aerospace Engineering Test Establishment at CFB Cold Lake for providing excellent facilities; the crew from SED Systems, Saskatoon and B. Wetter and R. Colley of the Space Research Facilities Branch (SRFB) who launched the payload in extreme temperatures of -30 to $-40^{\circ} \mathrm{C}$. We thank W.F.J. Evans and associates at AES for field support and for launching the sondes. We thank J.C. McConnell for discussions and for the results from his model. SRFB provided the launch expenses. The experiment was supported by the Natural Sclences and Engineering Council of Canada and by the AES.

\section{References}

Evans, W.F.J., J.B. Kerr, R.S. O'Brien, C.T. McElroy and J.C. McConnell, Measurements of $\mathrm{NO}_{2}$ and $\mathrm{HNO}_{3}$ during a stratospheric warming at $54^{\circ} \mathrm{N}$ in February 1979, Geophys. Res. Lett., this issue.

Hilsenrath, E., Rocket observations of the vertical distribution of ozone in the polar night and during a mid-winter stratospheric warming, Geophys. Res. Lett., 7, 581-584, 1980.

Madronich, S., D.R. Hastie, H.I. Schiff and B.A. Ridley, Measurements of the photodissociation coefficient of $\mathrm{NO}_{2}$, in preparation.

Murcray, D.G., J.W. Williams, D.B. Baker, A. Goldman, C. Bradford and G. Cook, Measurements of constituents of interest in the photochemistry of the ozone layer using infrared techniques, WMO Symposium on the Geophysical Aspects and Consequences of Changes in the Composition of the Stratosphere, Toronto, 26-30 June, 1978, WMO-no. 511 pp. $61-68$.

Noxon, J.F., Stratospheric $\mathrm{NO}_{2}$ : Global behaviour, J. Geophys. Res., 85, 4560-4561, 1979.

Noxon, J.F., E. Marovich and R.B. Norton, Effect of a major warming upon stratospheric $\mathrm{NO}_{2}, \mathrm{~J}$. Geophys. Res., 84, 7883-7888, 1979.

Noxon, J.F., Correction, J. Geophys. Res., 85, $4560-4561,1980$.

Quiroz, R.S., Tropospheric-stratospheric interaction in the major warming event of JanuaryFebruary 1979, Geophys. Res. Lett., 6, 645$648,1979$.

Ridley, B.A. and D.R. Hastie, Stratospheric oddnitrogen: NO measurements at $51^{\circ} \mathrm{N}$ in summer, J. Geophys. Res., 86, 3162-3166, 1981.

Ridley, B.A. and H.I. Schiff, Stratospheric oddnitrogen: Nitric oxide measurements at $32^{\circ} \mathrm{N}$ in autumn, J. Geophys. Res., 86, 3167-3172, 1981.

Syed, M.Q. and A.W. Harrison, Behavlour of stratospheric $\mathrm{NO}_{2}$ during stratospheric warming of January-February 1979, Atmosphere-Ocean, 19 , $216-235,1981$.

(Recelved January 5, 1982; accepted February 26, 1982.) 